\title{
Overwintering strategies in Calanus finmarchicus
}

\author{
Alasdair Hind ${ }^{1}$, William S. C. Gurney ${ }^{1, *}$, M. Heath ${ }^{2}$, A. D. Bryant ${ }^{2}$ \\ ${ }^{1}$ Department of Statistics and Modelling Science, University of Strathclyde, Glasgow G1 1 XH, Scotland, UK \\ ${ }^{2}$ Fisheries Research Services, Aberdeen Marine Laboratory, Aberdeen AB9 8DB, Scotland, UK
}

\begin{abstract}
The marine copepod Calanus finmarchicus is known to overwinter at depth in a state analogous to diapause in terrestrial insects, but the cues which cause individuals to enter and leave this state are the subject of speculation. In this paper we use a simple demographic model, driven by environmental data from 4 distinct locations in the organism's eastern range, to test the plausibility of a number of candidate mechanisms. We start from Miller et al.'s (1991; Mar Ecol Prog Ser 72:79-91) hypothesis that diapause is controlled by photoperiod, and show that this leads to unrealistic patterns of reproductive activity in northern waters. We extend the model to include the recently reported phenomenon (Hirche 1996a; Ophelia 44:111-128) of delayed gonad maturation in females experiencing low food concentrations. This yields more plausible annual patterns, but fails to reproduce observed geographical variation in the timing of the yearly onset of reproductive activity. Our final model dispenses with photoperiodic control and assumes that diapause duration is controlled by the normal development processes operating at a reduced rate. This model reproduces all the qualitative features of the patterns of reproductive activity observed at our 4 test sites, thus demonstrating that photoperiod cueing is not a necessary prerequisite for the regular re-ascension of $C$. finmarchicus into surface waters.
\end{abstract}

KEY WORDS: Calanus $\cdot$ Diapause $\cdot$ Overwintering $\cdot$ Life-cycle modelling

\section{INTRODUCTION}

The marine copepod Calanus finmarchicus is an important component of the pelagic food chain in much of the northern Atlantic and the Norwegian Sea. It forms an important part of the diet of a number of fish species which are commercially significant on the eastern seaboard of Canada and the United States, and on the western seaboard of Europe and Scandinavia. It has thus been the subject of considerable scientific study and much is known of its physiology, natural history and spatial distribution (e.g. Marshall \& Orr 1955, Østvedt 1955, Hirche 1996a,b).

However, one aspect of the interaction between Calanus finmarchicus natural history and its physiology remains enigmatic. Adults reproduce almost exclusively in surface waters and all life-history stages can be found in the top $50 \mathrm{~m}$ at certain times of year. In

\footnotetext{
•Corresponding author. E-mail: bill@stams.strath.ac.uk
}

winter, when surface waters contain few individuals in any developmental stage, large numbers of late juvenile copepedite stages (especially the final stage, C5) are found at depths below $500 \mathrm{~m}$ (Hirche 1996a). It is believed (Miller et al. 1991, Hirche 1996b) that this behaviour enhances overwinter survival by reducing both physiological costs and predation risk. Although physiological costs may simply be reduced by the low temperatures encountered at depth, it has been suggested that the copepods may also be undergoing physiological changes akin to those observed in terrestrial insects entering diapause (Hirche 1996b).

There are few direct observations of Calanus finmarchicus physiology in the conditions obtaining below $500 \mathrm{~m}$, due to the difficulty of replicating these conditions in the laboratory. Invarsdottir (1998) and Invarsdottir et al. (1999) have measured the respiration rates of animals recovered from depth at different times of year. They find that animals recovered in December and January show respiration rates between 20 and $50 \%$ lower than those exhibited at com- 


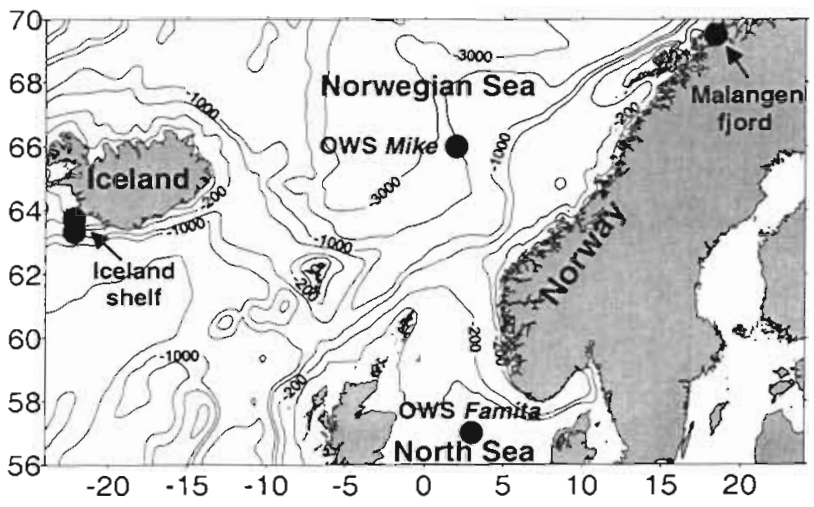

Fig. 1. Geographical location of the 4 test sites

parable temperatures by animals recovered in spring. These results suggest that the physiology of overwintering animals is significantly different from that of active ones, but give no information on the environmental cues which initiate or reverse this physiological adjustment.

Miller et al. (1991) suggest that exit from diapause may be photoperiodically cued. This mechanism is commonly implicated in insect diapause, and would undoubtedly be capable of producing temporal changes in vertical distribution with qualitative similarities to those observed in the field. To test this hypothesis, Miller \& Grigg (1991) recovered individuals overwintering at depths of around $100 \mathrm{~m}$ in the Gulf of Maine and observed their further development in the laboratory under different light regimes. They found that only continuous light and (undefined) disturbance promoted arousal and completion of development, which otherwise proceeded independently of the imposed light regime. They conclude that their experiments neither confirm nor refute the hypothesis of photoperiodic cueing.

In addition to a lack of positive experimental support, the photoperiodic cueing hypothesis suffers from 2 quite serious conceptual difficulties. First, it requires an individual living in the very low light levels prevalent at oceanic overwintering depths $(>500 \mathrm{~m}$ ) to have an accurate perception of daylength. Second, there is little evidence of genetic differentiation between Calanus finmarchicus stocks at ocean basin scales (Bucklin et al. 1996) and even less of more local variability. Observed geographical variation of population cycle timing must thus be explicable (at least on a sub-basin scale) using a single set of genetically determined rules.

In the absence of any realistic possibility of direct refutation of the photoperiodic cueing hypothesis, it seems sensible to subject it to any indirect test which we are able to devise. In this paper we use a strategic model of Calanus finmarchicus demography, driven by environmental data from 4 locations in the organism's eastern range, to test 3 hypothetical mechanisms of diapause control against available information on geographical life-history variation. The simplicity and computational efficiency of our model enables us to obtain almost complete coverage of the unknown parts of the model parameter space, and thus assure ourselves that the observed behaviour is robust.

We show that the observed features of Calanus finmarchicus geographical oceanography can most easily be explained by postulating that diapause initiation is controlled by low food availability and its duration is controlled by a close relative of the normal development processes. Moreover, we show that the very restrictive requirement of genetic uniformity makes any purely photoperiodic hypothesis very likely to be falsified.

\section{THE MODELLING FRAMEWORK}

Individuals. The life-history of Calanus finmarchicus starts as an egg $(E)$, and progresses through 6 naupliar stages ( $\mathrm{N} 1$ to $\mathrm{N} 6$ ) followed by 5 juvenile copepedite stages ( $\mathrm{C} 1$ to $\mathrm{C} 5$ ), before it enters the final copepedite stage and becomes an adult. Since egg production does not commence immediately after the last molt, we further subdivide the final stage into a period of immaturity, for which we use the designation $C 6$, and a subsequent period of reproductively active life, which we designate as adulthood $(A)$.

To describe the individual's development through these 14 stages we follow Hind \& Gurney (1998) and define a cumulative development index, $c$, whose value starts at 0 for a newly released egg and increases by 1 through each life-history stage. Thus, any individual with $0 \leq c<1$ is an egg, any individual with $1 \leq c<$ 2 is in stage N1, and so on. For future notational convenience we also define a numerical stage designation $(s)$ which starts at 0 for the egg stage and runs to 13 for reproductively active adults. This quantity is just the integer part of the cumulative development index, so that

$$
s=\operatorname{int}(c)
$$

A full list of stage names, cumulative development ranges and stage numbers is given in Table 1.

Individuals in early life-history stages and gravid adults are only found in surface waters throughout the year. However, during winter, late copepedite stages are found predominantly at depth, where they are assumed to have an increased chance of surviving until the following spring. As a strategic simplification we assume that all stages between egg and $\mathrm{C} 4$ exist 
only in surface waters, which we define as being waters between the surface and a depth $Z_{s}$.

Miller \& Tande (1993) and Hind \& Gurney (1998) make the simplifying assumption that the duration of all Calanus finmarchicus life-history stages depends only on the environmental temperature $(T)$. We largely follow the same pattern, and determine the development rate for individuals in stage $s, d(s)$, from observed stage durations for individuals raised at constant temperature-which, given our definition of the development index, are simply the inverse of the equivalent development rates.

Our assumption that Stages N1 to C4 are confined to surface waters implies that they are not exposed to temperatures lower than a few degrees Celsius (see Fig. 2). This permits us to adopt a very simple parametric representation of the development rate

$$
d(s)=A_{s} T^{p_{s}}
$$

Fits of this function to the data of Tande (1988) and Campbell (pers. comm.) are given in Table 1.

For Stages C5 and C6 the development rules will differ in our 3 model variants. At this stage we derive a basic representation of the 'normal' temperature dependence of development though Stage C5. Since individuals at depth may be exposed to temperatures
Table 1 Stage designations and normal development rates

\begin{tabular}{|lccc|}
\hline $\begin{array}{l}\text { Stage } \\
\text { name }\end{array}$ & $\begin{array}{c}\text { Development } \\
\text { index range }(c)\end{array}$ & $\begin{array}{c}\text { Stage no. } \\
(s)\end{array}$ & $\begin{array}{c}\text { Development rate } \\
\left(d^{-1}\right)\end{array}$ \\
\hline$E$ & $0 \leq c<1$ & $s=0$ & $d(0)=0.109 T^{0.8}$ \\
N1 & $1 \leq c<2$ & $s=1$ & $d(1)=0.168 T^{0.8}$ \\
N2 & $2 \leq c<3$ & $s=2$ & $d(2)=0.112 T^{0.8}$ \\
N3 & $3 \leq c<4$ & $s=3$ & $d(3)=0.047 T^{0.8}$ \\
N4 & $4 \leq c<5$ & $s=4$ & $d(4)=0.086 T^{0.8}$ \\
N5 & $5 \leq c<6$ & $s=5$ & $d(5)=0.091 T^{0.8}$ \\
N6 & $6 \leq c<7$ & $s=6$ & $d(6)=0.077 T^{0.8}$ \\
C1 & $7 \leq c<8$ & $s=7$ & $d(7)=0.067 T^{0.8}$ \\
C2 & $8 \leq c<9$ & $s=8$ & $d(8)=0.057 T^{0.8}$ \\
C3 & $9 \leq c<10$ & $s=9$ & $d(9)=0.021 T$ \\
C4 & $10 \leq c<11$ & $s=10$ & $d(10)=0.020 T^{0.8}$ \\
C5 & $11 \leq c<12$ & $s=11$ & See text \\
C6 & $12 \leq c<13$ & $s=12$ & See text \\
A & $13 \leq c$ & $s=13$ & $d(13)=0$ \\
\end{tabular}

below 0 the functional form in Eq. (2) is clearly inappropriate. Instead we choose a piecewise-linear form and find that the best fit to the development rate data is

$$
d_{n}(11)= \begin{cases}(18.74-0.935 T)^{-1} & \text { if } T \geq 6 \\ (109.2-12.27 T)^{-1} & \text { otherwise }\end{cases}
$$

We assume that C5 individuals may choose between remaining at the surface or sinking (at a rate $\sigma_{\mathrm{s}}$ ) until they reach an overwintering depth $\left(Z_{w}\right)$ which we take to be $600 \mathrm{~m}$ in oceanic waters (Hirche 1996b, Heath \& Jonasdotir 1999), and the bottom in shelf waters. During sinking, development is suspended. Once at depth, development may recommence, possibly at a reduced rate.

At some point, the individual must choose to return to the surface and complete its development into a mature adult. Once this choice has been made we assume that the animal rises at a rate $\sigma_{r}$ until it reaches the surface. We follow Bryant et al. (1998) in setting $\sigma_{\mathrm{s}}=15 \mathrm{~m} \mathrm{~d}^{-1}$ and $\sigma_{\mathrm{r}}=-15 \mathrm{~m} \mathrm{~d}^{-1}$. The cues which control onset and termination of overwintering behaviour are the principal subject of this paper, so we shall reserve further discussion of the details of depth control and a detailed description of the rules governing development of Stages C5 and C6 until the next section.

Once an individual reaches the adult (A) stage we assume that it begins to produce eggs. Data given in Hirche et al. (1997) show a strong relation between fecundity and both environ-
Fig. 2. Estimated annual cycle of temperature (dotted line) and phytoplankton carbon (solid line) at the 4 test sites. The downward arrow indicates the onset of reproduction at each site, and the horizontal dashed line indicates the critical food level below which (under Strategies I and M) immature C6 individuals delay ripening their gonads and individuals moulting from $\mathrm{C} 4$ to $\mathrm{C} 5$ initiate overwintering behaviour 
mental temperature and food concentration. As a strategic simplification we neglect temperature effects and fit the food effect data by writing the daily egg production of an adult experiencing a food concentration $\mathrm{Fmg} \mathrm{C} \mathrm{m}^{-3}$ as

$$
\beta(F)=2.23 F^{0.417}
$$

Very little is known about the mortality of individual Calanus finmarchicus, so we shall make a series of strategic assumptions and demand that our model be robust against variations in these assumptions. We divide the total mortality rate into 3 componentsbackground $\left(m_{b}\right)$, food dependent $\left(m_{f}\right)$, and density dependent $\left(m_{d}\right)$. In the absence of any information about how these quantities vary with age or stage, we assume them to be stage independent-with the exception of stage C6 individuals returning from overwintering, who are assumed to carry a store of reserves which exempts them from food-dependent mortality for $(R)$ days. Values of the metabolic rates of late copepedites and the energy content of eggs (thought to form the bulk of the reserves) given by Ingvarsdottir et al. (1999), Richardson et al. (1999) and Jonasdottir et al. (1999) lead us to estimate the value of $R$ as $30 \mathrm{~d}$.

We assume the background mortality rate to have a constant value corresponding to $1 \%$ loss per day, that is $m_{\mathrm{b}}=0.01 \mathrm{~d}^{-1}$. We take the food-dependent component of mortality as representing only those effects which occur as a result of severe food shortage, so we assume that $m_{\mathrm{f}}$ is 0 when food abundance exceeds a critical value $F_{m}$ and rises to infinity as $F \rightarrow 0$. A convenient formulation with this property is

$$
m_{\mathrm{f}}= \begin{cases}0 & \text { if } F>F_{m} \\ \ln \left(F_{m} / F\right) & \text { otherwise }\end{cases}
$$

which further implies that the survival through any finite increment is unity for $F>F_{m}$ and falls linearly to 0 with $F$ below this value. From data on the respiration rate of active $\mathrm{C} 5$ and $\mathrm{C} 6$ copepedites in the absence of food (Ingvarsdottir et al. 1999), assimilation efficiency (Kiørboe 1989) and clearance rate (Paffenhoffer 1971) we estimate the food concentration below which an individual cannot meet its maintenance costs (a plausible value for $F_{m}$ ) as $5 \mathrm{mg} \mathrm{C} \mathrm{m}^{-3}$.

Steele \& Henderson (1995) and Truscott \& Brindley (1994) have argued that the effects of predation on zooplankton populations can be adequately represented by assuming a predation mortality rate which is linearly dependent on the total zooplankton density. Following their lead, we write

$$
m_{\mathrm{d}}=\phi N
$$

where $N$ is the total density of Calanus finmarchicus and $\phi$ is a constant of proportionality.
The population. We regard the population as being composed of age-classified cohorts, and write the spatial density of females (number $\mathrm{m}^{-2}$ ) in age range $a \rightarrow a+\Delta$ at time $t$ as $n_{a, t}$. We assume that the population is closed to immigration and emigration, so we can regard all individuals in a given age-class at a given time as having been exposed to the same environmental history. Provided that $\Delta$ is not too big, we can satisfactorily equate the developmental state of all the individuals in an age-class to the class-averaged value $c_{a, t}$. We calculate the total density of individuals $\left(N_{t}\right)$ by summing the contents of all cohorts, and the total density of adults $\left(A_{t}\right)$ by summing cohorts with $c \geq 13$, so

$$
N_{\mathrm{t}}=\sum_{\mathrm{au} a} n_{a, t} \quad A_{\mathrm{t}}=\sum_{c \geq 13} n_{a, t}
$$

We use a discrete-time framework with a time increment equal to the age-class range, so that all survivors of the group of individuals found in age-class a at time $t$ must be members of age-class $a+\Delta$ at time $t+\Delta$ Hence, the update rule for the age-distribution is

$$
n_{a+\Delta, t+\Delta}= \begin{cases}\xi_{a, t} n_{\partial, t} & a+\Delta<0 \\ \beta\left(F_{\mathrm{t}}\right) A_{\mathrm{t}} \Delta & a+\Delta=0\end{cases}
$$

The updated content of age-class 0 is determined by total egg production during the time increment, which in turn depends on the per-capita fecundity $\beta$, and hence on the environmental food concentration $F_{1}$ (see Eq. 4). The update of all other age-classes is dependent on the through-class survival $\xi_{a, t}$, which is in turn related to the per-capita mortality rate. For individuals at the surface, total mortality is the sum of background, food-and density-dependent contributions. However, individuals overwintering at depth are protected from predation (density-dependent mortality) and carry food reserves which prevent food-dependent mortality. Hence, if we represent the position in the water column occupied by individuals in age-class a at time $t$ by $z_{a, t}$, then we can write the through age-class survival as

$$
\xi_{a, t}= \begin{cases}\mathrm{e}^{-\left(m_{\mathrm{b}}+m_{\mathrm{l}}+m_{\mathrm{d}}\right) \Delta} & Z_{a, t} \leq Z_{\mathrm{s}} \\ \mathrm{e}^{-m_{\mathrm{b}} \Delta} & \text { otherwise }\end{cases}
$$

The developmental state of a cohort changes with time, so we need an update rule for the cohort-average cumulative development $C_{a, t}$. We have already defined $d(s)$ to represent the development rate of an individual in stage $s$, and we recall that stage index (s) and cumulative development $(c)$ are related by Eq. (1). Thus, provided the model time-increment is not too large, the appropriate update rule for cumulative development is

$$
c_{a+\Delta, t+\Delta}=c_{a, t}+d\left(s_{a, t}\right) \Delta \quad s_{a, t} \equiv \operatorname{int}\left(C_{a, t}\right)
$$

where $d(s)$ is defined for Stages 1 to 11 and 13 (i.e. E to 
C4 and $A$ ) in Table 1 and will be defined for Stages C5 and $\mathrm{C} 6$ below.

We see from Table 1 that development rate is determined by local water temperature, which is in turn determined by both time of year and position in the water column. Given the cohort's vertical position $z_{a, t}$, we determine the appropriate temperature by linear interpolation between an observed (time-dependent) surface temperature and a (constant) bottom temperature.

Since our model assumes that an individual's position in the water column can vary, we regard the cohort's average vertical position $Z_{a, t}$ as a dynamic variable for which we require an update rule. The details of this update rule depend on diapause control strategy and will therefore be deferred until the next section. However, it turns out to enhance the compactness of our representation if we also regard the average sinking rate of the cohort $\sigma_{a, t}$ as a dynamic variable. The formal statement of the update rule for cohort depth is then

$$
z_{a+\Delta, l+\Delta}=z_{a, l}+\sigma_{a, l} \Delta
$$

\section{DIAPAUSE CONTROL}

In this section, we set out 3 possible strategies by which diapause in Calanus finmarchicus might be controlled. As a strategic simplification we assume that only C5 individuals can diapause.

Daylength - Strategy D. Many terrestrial instances of diapause are controlled by photoperiodic cues and Miller et al. (1991) have suggested that similar mechanisms may provide the cue for Calanus finmarchicus to ascend from deep overwintering in the Gulf of Maine. Our first candidate control mechanism thus assumes that daylength, which we calculate as a function of latitude and Julian day according to the prescription of Iqbal (1983), determines the onset and termination of overwintering behaviour.

We assume that any animal which moults from $\mathrm{C} 4$ to C5 ( $s=10 \rightarrow s=11$ ) will initiate overwintering behaviour if current daylength, $L_{t}$, is below a threshold value $L_{\mathrm{E}}$ and falling. In this event, the animal suspends development and starts sinking at a rate $\sigma_{\mathrm{s}}$. This continues until the animal reaches the overwintering depth $Z_{w}$ where it remains, with development suspended, until $L_{t}$ increases past a critical value $L_{X}$, whereupon development restarts and the animal rises at a rate $\sigma_{\mathrm{r}}$ until it reaches the surface $\left(Z_{\mathrm{s}}\right)$. At the end of developmental stage $\mathrm{C} 5$, the animal moults to $\mathrm{C} 6$ and takes exactly $2 \mathrm{~d}$ to ripen its gonads and begin egg production.

The equations which complete this instance of our model, which we call Strategy D, comprise an update rule for the sinking-rate state variable $\left(\sigma_{a, t}\right)$

$$
\sigma_{a+\Delta, t+\Delta}= \begin{cases}\sigma_{\mathrm{s}} & s_{a, t}=10, s_{a+\Delta, t+\Delta}=11 \text { and } L_{t+\Delta}<L_{t}<L_{\mathrm{E}} \\ 0 & z_{a, t} \geq Z_{\mathrm{w}} \text { and } \sigma_{a, t}=\sigma_{\mathrm{s}} \\ \sigma_{\mathrm{r}} & z_{a, t} \geq Z_{\mathrm{w}}, \sigma_{a_{t} t}=0 \text { and } L_{t+\Delta}>L_{t}>L_{\mathrm{X}} \\ 0 & z_{a, t} \leq Z_{\mathrm{s}} \text { and } \sigma_{a, t}=\sigma_{\mathrm{r}} \\ \sigma_{a, t} \text { otherwise }\end{cases}
$$

and definitions for the development rate function for Stages C6 and C5, which we write

$$
\begin{aligned}
& d(12)=0.5 \\
& d(11)= \begin{cases}d_{n}(11) & \text { if } z_{a, t} \leq Z_{s} \text { or } \sigma_{a, t}=\sigma_{r} \\
0 & \text { otherwise }\end{cases}
\end{aligned}
$$

Normal development for stage $C 5\left[d_{n}(11)\right]$ is described by Eq. (3).

Daylength and gonad maturation-Strategy $\mathbf{M}$. One aspect of Calanus finmarchicus biology which the Strategy D variant omits is delayed reproductive development. Evidence reviewed by Hirche (1996a) suggests that gonad maturation in female $C$. finmarchicus is dependent upon the exsitence of a 'sufficient' food supply. We model this possibility by assuming that immature C6 individuals do not develop into adults unless the environmental food density $F_{\mathrm{t}}$ exceeds a critical value $F_{\mathrm{G}}$, that is we define

$$
d(12)= \begin{cases}0.5 & \text { if } F_{\mathrm{t}}>F_{\mathrm{G}} \\ 0 & \text { otherwise }\end{cases}
$$

In this instance of the model, hereafter referred to as Strategy M, we continue to assume that the development function for Stage C5 is given by Eq. (14).

It is hard to see why an animal should continue developing towards adulthood when it will not be able to ripen its gonads when it gets there. Thus, although we continue to assume that exit from diapause is controlled by photoperiod, we now assume that sinking occurs when an individual moults from C4 to C5 and finds herself in a food environment too impoverished to permit an adult to ripen her gonads. That is we set

$$
\sigma_{a+\Delta, t+\Delta}= \begin{cases}\sigma_{\mathrm{s}} & s_{a, t}=10, s_{a+\Delta, t+\Delta}=11 \text { and } F_{\mathrm{t}}<F_{\mathrm{G}} \\ 0 & z_{a, t} \geq Z_{\mathrm{w}} \text { and } \sigma_{a, t}=\sigma_{\mathrm{s}} \\ \sigma_{\mathrm{r}} & z_{a, t} \geq Z_{\mathrm{w}}, \sigma_{a, t}=0 \text { and } L_{t+\Delta}>L_{t}>L_{\mathrm{X}} \\ 0 & z_{a, t} \leq Z_{\mathrm{s}} \text { and } \sigma_{a, t}=\sigma_{\mathrm{r}} \\ \sigma_{a, t} & \text { otherwise }\end{cases}
$$

Non-cued diapause exit-Strategy I. Previous strategic studies of synchronisation between life-cycles and periodic environmental cues (Gurney et al. 1994, Grist \& Gurney 1995) have shown that a multi-stage life-cycle will synchronise to a periodic environment provided that at least 1 stage responds to the environment sufficiently differently from the remainder. We see that the Strategy $M$ variant contains 2 mechanisms (photocued diapause exit and food delayed gonad 
maturation), each potentially capable of synchronising Calanus finmarchicus life-cycle to an annual environmental cycle.

In the final (Strategy I) model variant, we explore the possibility that synchronisation takes place without any photoperiod cueing. We continue to assume that animals moulting from $\mathrm{C} 4$ to $\mathrm{C} 5$ will sink if $F_{\mathrm{t}}<F_{\mathrm{G}}$ and will stop developing while sinking. However, when they reach overwintering depth, we assume (in accordance with the respirometry data of Ingvarsdottir et al. 1999) that the development rate is reduced by a constant factor $\Gamma$ relative to that of an animal in surface waters at the same temperature. Thus we now define the C 5 development function as

$$
d(11)= \begin{cases}d_{n}(11) & z_{a, t} \leq Z_{\mathrm{s}} \text { or } \sigma_{a, t}=\sigma_{\mathrm{r}} \\ 0 & \sigma_{a, t}=\sigma_{\mathrm{s}} \\ \Gamma d_{n}(11) & \text { otherwise }\end{cases}
$$

where the normal C5 development rate $\left\{d_{n}(11)\right]$ is given by Eq. (3)

We assume further that an individual begins to reascend to the surface when stage C 5 is $80 \%$ complete. The update rule for the sinking rate $\sigma_{a, t}$ thus becomes

$$
\sigma_{a+\Delta, t+\Delta}= \begin{cases}\sigma_{s} & s_{a, t}=10, \quad s_{a+\Delta, t+\Delta}=11 \text { and } F_{\mathrm{t}}<F_{\mathrm{G}} \\ 0 & z_{a, t} \geq Z_{\mathrm{w}} \text { and } \sigma_{a, t}=\sigma_{\mathrm{s}} \\ \sigma_{\mathrm{r}} & Z_{a, t} \geq Z_{\mathrm{w}}, \text { and } c_{a, t} \geq 11.8 \\ 0 & z_{a, t} \leq Z_{\mathrm{s}} \text { and } \sigma_{a, t}=\sigma_{\mathrm{I}} \\ \sigma_{a, t} & \text { otherwise }\end{cases}
$$

We continue to assume that the development function for immature adults (C6) is given by Eq. (15).

\section{COMPARING THE THREE STRATEGIES}

\section{Four test locations}

To test our 3 candidate mechanisms we have assembled data from 4 contrasting sites within the eastern range of Calanus finmarchicus. These locations, which are shown in Fig. 1, cover a latitudinal range from $57^{\circ} \mathrm{N}$ to nearly $70^{\circ} \mathrm{N}$, and comprise 2 coastal sites (Malangen Fjord and Iceland) and 2 non-coastal locations (Ocean Weather Ships Mike and Famita).

We estimated the annual cycle of surface temperature and phytoplankton carbon at each location from the following sources: Malangen-Falkenhaug et al. (1997a), and Falkenhaug (1996); OWS Mike-Irigioen et al. (1998), Melle \& Ellertsen (unpubl.); IcelandGislasson \& Asthorsson (1996); OWS Famita - Carlotti \& Radach (1996). The assumed overwintering depths and bottom temperatures were: OWS Mike-600 m and $1^{\circ} \mathrm{C}_{i}$ Iceland shelf $-600 \mathrm{~m}$ and $1^{\circ} \mathrm{C}$; OWS Famita$60 \mathrm{~m}$ and $4^{\circ} \mathrm{C}$; Malangen Fjord $-300 \mathrm{~m}$ and $6^{\circ} \mathrm{C}$.

In each case we converted measurements of chlorophyll a to carbon concentration using a conversion factor of 40 (Hirche \& Kwasniewski 1997). It is recognised that, under some circumstances, Calanus finmarchicus may indulge in omnivory and supplement their diet with microzooplankton (Ohman \& Runge 1994). However, it is unclear how widespread such behaviour may be. Studies which have demonstrated significant ingestion of microzooplankton have generally been in productive summer situations. In contrast, Richardson et al. (1999) estimated that microzooplankton could account for only about $1 \%$ of the carbon ingested by a female $C$. finmarchicus during spring in the oceanic North Atlantic. In any case, the abundance of ciliates and other microzooplankton is generally highly correlated with phytoplankton when viewed with monthly resolution over an annual cycle. Thus, failure to take account of omnivory is effectively accomodated in uncertainty around the fixed carbon:chlorophyll ratio adopted here.

To avoid undue dependence of our results on (unknown) starting conditions, we need to run the model over a number of years and determine the stable pattern of reproductive behaviour. Our input data generally cover only a single year, so we created multiyear driving functions by repeated concatenation of the single-year cycle estimates.

To test the model predictions we estimated the time of first reproduction and the number of generations before re-entry to diapause at each site. These data, together with the physical data used to drive the model at each site, are summarised in Fig. 2. The sources used were: Malangen fjord-Falkenhaug et al. (1997a,b); OWS Mike-Østvedt (1955), Irigoen et al. (1998); Iceland-Gislasson et al. (1996); OWS Famita-Carlotti \& Radach (1996). Where possible, we estimated the timing of first reproduction by back calculation from the time of year at which significant numbers of $\mathrm{C} 1$ individuals were first detected.

In the case of Malangen fjord our estimate of more than 2 generations per year is somewhat at variance with the conventional view. We base it on the data given in Fig. 3 of Falkenhaug et al. (1997a). Their Fig. 3b shows that significant numbers of adult female Calanus finmarchicus are present in the surface waters in every month surveyed between February and December. Their Fig. 3a shows that significant numbers of $\mathrm{C} 1$ individuals are found in April, July and August, with trace numbers present in May, June and September. Since the maximum duration of the Stage C1 is 5 to $6 \mathrm{~d}$ and the total life-cycle time without diapause is roughly $1 \mathrm{mo}$, this clearly indicates at least 3 separate generations per year - albeit of considerably different sizes. 
a)
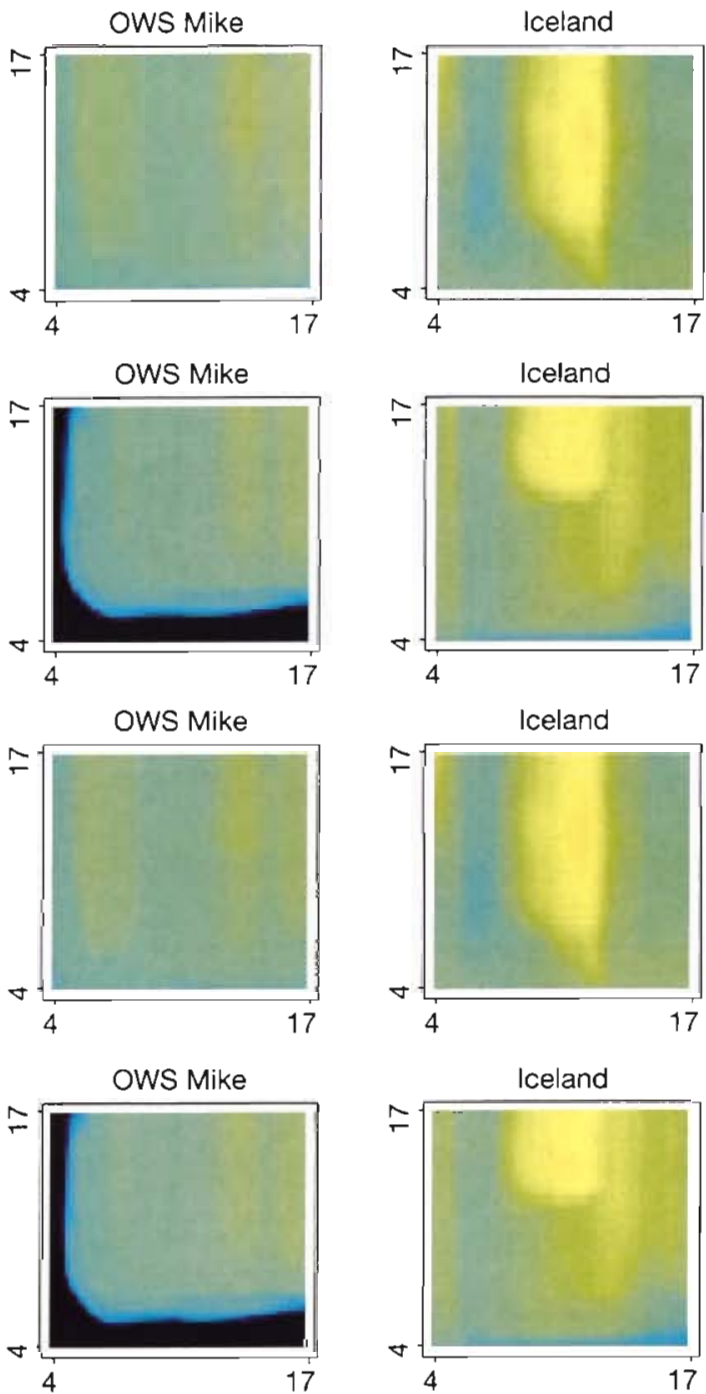
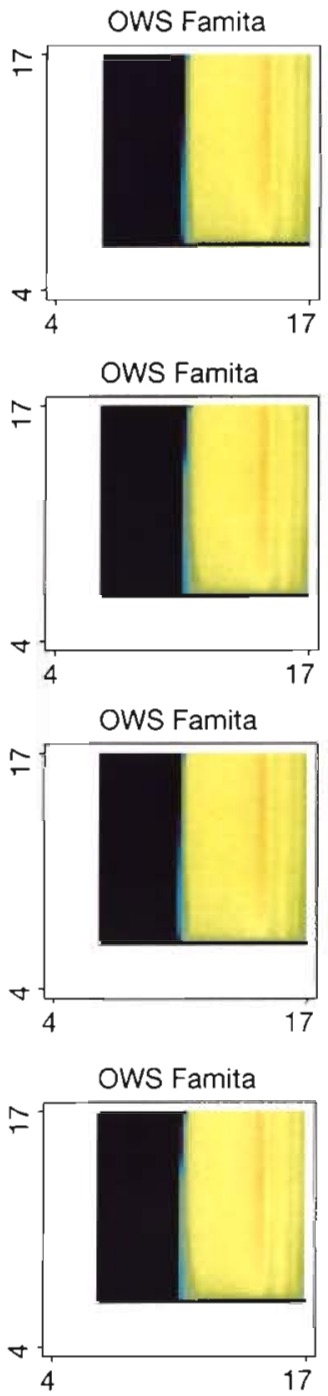
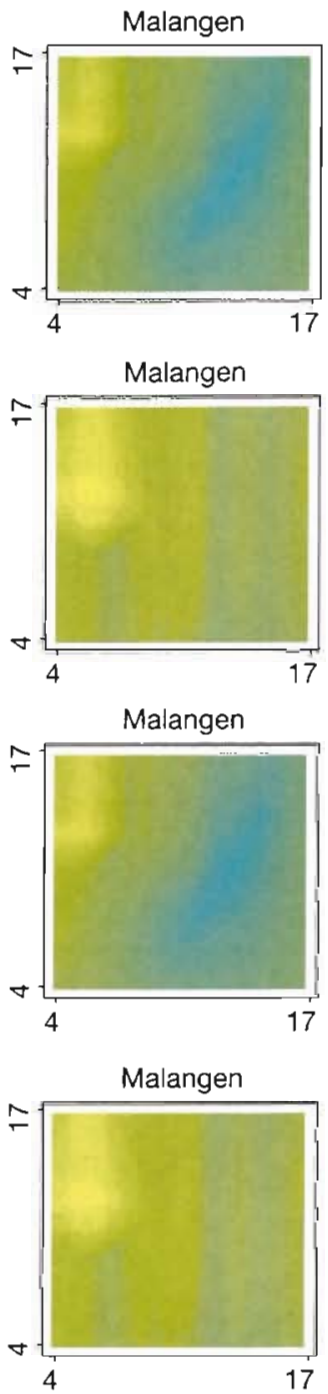

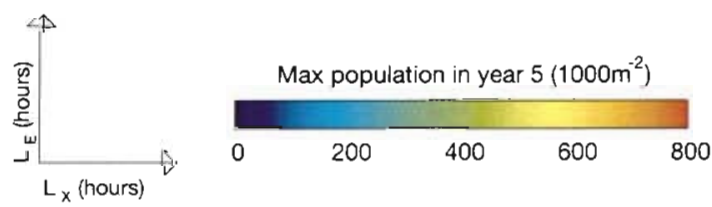

Fig. 3. Variation of population persistence under diapause control Strategy D as the cue daylengths for initiation $\left(L_{E}\right)$ and exit $\left(L_{X}\right)$ are varied. (a) Year 5 maximum population at 4 test sites with $F_{m}=5 \mathrm{mg} \mathrm{C} \mathrm{m}^{-3}$ and $R=30 \mathrm{~d}$, (b) Year 5 maximum population with $F_{m}=10 \mathrm{mg} \mathrm{C} \mathrm{m}^{-3}$ and $R=30 \mathrm{~d}$, (c) $F_{m}=5 \mathrm{mg} \mathrm{C} \mathrm{m}^{-3}$ and $R=0 \mathrm{~d}$, (d) $F_{m}=10 \mathrm{mg} \mathrm{C} \mathrm{m}{ }^{-3}$ and $R=0 \mathrm{~d}$. All simulations started with 100 immature adults in the surface on March 17 of Year 1 and had $\phi=4.32 \times 10^{-7} \mathrm{~d}^{-1} \mathrm{~m}^{-2}$

\section{Testing methodology}

Bucklin et al. (1996) show that Calanus finmarchicus from different regions of the Eastern Atlantic and Norwegian Sea have sufficient genetic similarity to be seen as a single population. Since the rules which govern an individual's response to its physical and biotic environment must be genetically determined, this suggests that these rules should be uniform across all our test sites. We thus regard an instance of the model as being falsified if it fails to pass a given test using a single set of biological parameters across all 4 sites.

We cannot realistically expect our highly simplified strategic model to make accurate predictions of the annual cycle of Calanus finmarchicus density at each test site-a quantity which, in any case, we do not know for all sites. Instead we shall regard a model instance as being falsified if it fails to predict prolonged 
persistence, accompanied by a qualitatively realistic annual cycle of reproductive activity, at all 4 sites.

Although we have acceptable estimates of many of the functions and parameters which define the model, both the density-dependent mortality coefficient ( $\phi$ ) and the diapause control parameters are entirely unknown. The qualitative nature of our tests implies that the absolute value of the $\phi$ will not affect their outcome. Thus, we arbitrarily choose a value which ensures that the peak total abundance in the first year of a simulation at OWS Famita, started with appropriate initial conditions, matches the predictions of Carlotti \& Radach (1996). Since Carlotti \& Radach's simulation star-
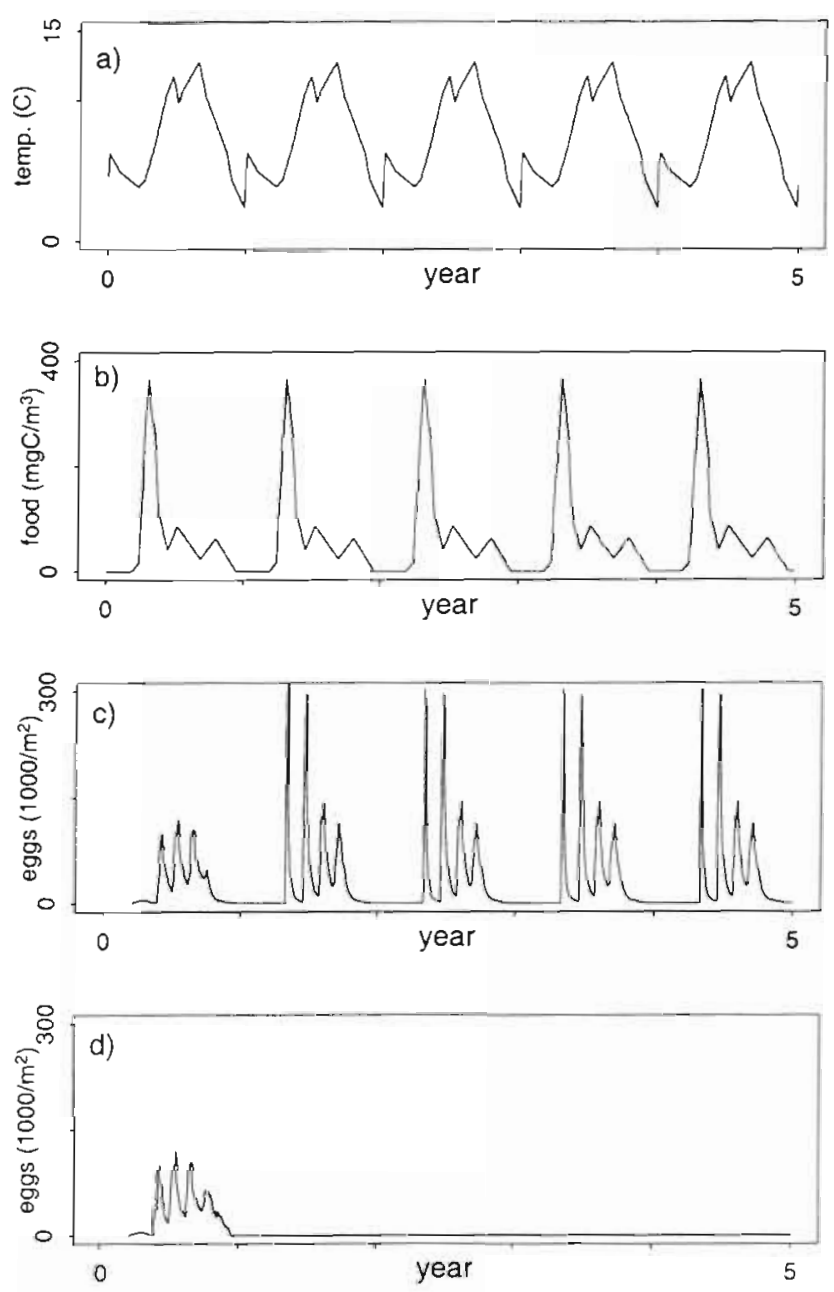

Fig. 4. Predicted reproductive dynamics of Calanus finmarchicus driven by the environmental conditions at OWS Famita. (a) Surface temperature (b), surface food concentration, (c) egg abundance under diapause control Strategy D, and (d) egg abundance when overwintering at depth is suppressed. Both simulations were started on 17 March with 100 inmature adults (C6) at the surface. Parameters: $F_{m}=5 \mathrm{mg} \mathrm{C}$ $\mathrm{m}^{-3}, R=30 \mathrm{~d}, L_{\mathrm{X}}=L_{E}=12 \mathrm{~h}, \phi=4.32 \times 10^{-7} \mathrm{~d}^{-1} \mathrm{~m}^{-2}$ ted with a group of immature adults newly reascended to the surface, the required value $\left(\phi=4.32 \times 10^{-7} \mathrm{~d}^{-1}\right.$ Calanus finmarchicus ${ }^{-1} \mathrm{~m}^{-2}$ ) does not depend on the choice of diapause control rule.

In Fig. 4c we show the temporal variation in egg density predicted over 5 yr at OWS Famita by the Strategy $\mathrm{D}$ variant, starting from 100 immature C6 individuals in the surface waters on 17 March. Comparison with the assumed temporal variation of surface temperature and food shown in Fig. 4a,b demonstrates that from Year 2 onward, the population exhibits a stable annual cycle which is exactly synchonised with its annually varying environment.

In Fig. 4d we illustrate the predicted variation of egg numbers when C5 individuals are forced to overwinter in surface waters and are thus subject to food-dependent mortality throughout the winter. In this case the population cannot sustain itself, and is extinct by the spring of Year 2.

These numerical experiments demonstrate that the population variation rapidly converges to a stable annual cycle synchronised with the annual cycles in temperature and food abundance. We can thus compensate for our lack of knowledge of the diapause control parameter values by performing 5 yr simulation runs over a variety of values within the plausible range of the unknown parameters. Indeed, because of the computational efficiency of the model, the small number of unknown parameters, and the brevity of the required runs, our scanning process can achieve essentially complete coverage at very modest computational cost.

\section{Strategy D}

In Fig. 3a we show a series of portraits of the persistence behaviour of the Strategy $D$ variant, as the daylength cues for diapause entry and exit ( $L_{E}$ and $L_{X}$ respectively) are varied. At each point in the $L_{E}-L_{X}$ plane we start with $100 \mathrm{C} 6$ individuals in the surface on 17 March of Year 1 and plot a pixel whose colour reflects the maximum total population density in Year 5. A white pixel shows that the given $L_{E}-L_{X}$ combination cannot be attained at this site. A black pixel shows that the population was extinct after 5 yr. The attainable region of parameter space in which persistence occurs is thus the region filled with varying non-white shades.

Recalling that we require persistence to be obtainable with uniform values of $L_{E}$ and $L_{X}$ across all 4 sites, we see that the model passes the persistence test for all values of $L_{X}>9.8 \mathrm{~h}$ and all values of $L_{E}>$ $6.2 \mathrm{~h}$. In the lower frames of this figure we see that this pattern of behaviour is robust against removal of 

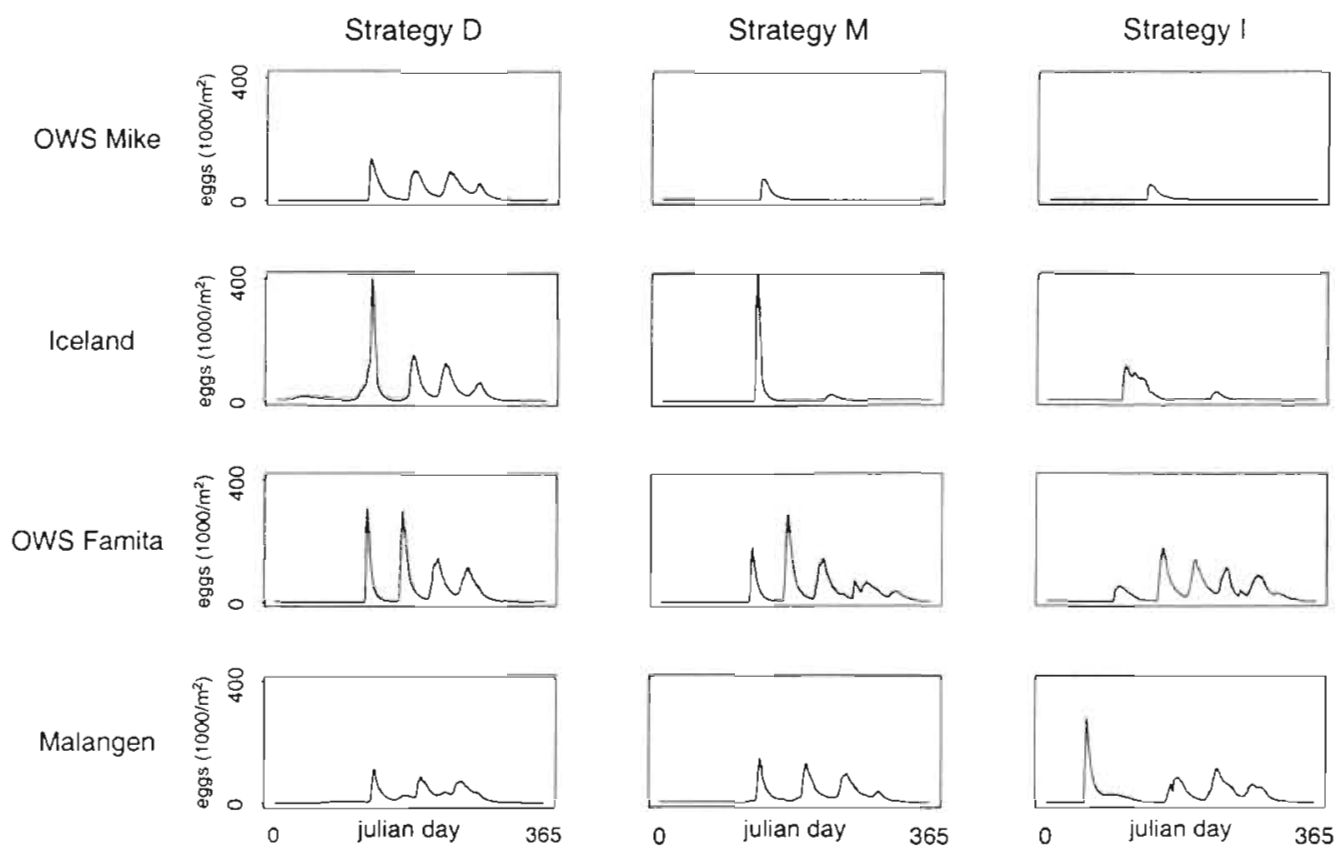

Fig. 5. Cannonical predictions of the stable annual cycle of egg abundance at the 4 test sites under each diapause control strategy. For Strategy D, $L_{\mathrm{E}}=L_{\mathrm{X}}=12 \mathrm{~h}$. For Strategy $\mathrm{M}, F_{\mathrm{G}}=30 \mathrm{mg} \mathrm{C} \mathrm{m}^{-3}$ and $L_{\mathrm{X}}=12 \mathrm{~h}$. For Strategy $\mathrm{I}, F_{\mathrm{G}}=30 \mathrm{mg} \mathrm{C} \mathrm{m}^{-3}$ and $\Gamma=0.5$

the reserves carried by an individual returning to the surface $(R \rightarrow 0)$ and doubling of food-dependent mortality $\left(F_{m} \rightarrow 10\right)$.

In Fig. 5 we show the stable annual cycle of egg abundance predicted at all 4 test sites with parameter values in the centre of the acceptable region $\left(L_{\mathrm{E}}=L_{\mathrm{X}}=\right.$ $12 \mathrm{~h})$. Although the prediction of 4 generations per year at OWS Famita and 3 in Malangen Fjord are by no means unrealistic, the patterns for both OWS Mike and the Iceland shelf differ notably from the accepted view of Calanus finmarchicus reproductive activity in these areas.

\section{Strategy $\mathbf{M}$}

In Fig. 6a we show a behaviour portrait illustrating the variation in maximum Year 5 density predicted by the Strategy $M$ model variant as we change the critical food density $\left(F_{G}\right)$ and the diapause exit daylength $\left(L_{X}\right)$. We see that with the default values of food-dependent mortality and reserves, the model passes the persistence test provided $L_{\mathrm{X}}>10 \mathrm{~h}$ and $F_{\mathrm{G}}<84 \mathrm{mg} \mathrm{C} \mathrm{m}^{-3}$ a conclusion which Fig. $3 b$ to $d$ show to be robust against removing reserves and doubling the fooddependent mortality coefficient.

In Fig. 5 we show the stable annual cycle of egg abundance predicted by this model variant with $F_{\mathrm{G}}=$ $30 \mathrm{mg} \mathrm{C} \mathrm{m}{ }^{-3}$ and $L_{X}=12 \mathrm{~h}$. We see that while the behaviour at OWS Famita and Malagen Fjord is barely changed, the patterns predicted at OWS Mike and on the Iceland shelf are more realistic, with a single peak at OWS Mike (Norwegian Sea) and 2 on the Iceland shelf.

However, we note that a further unrealistic feature of the Strategy D results remains essentially unchanged. Reproductive activity starts in the first $2 \mathrm{wk}$ of May at all 4 sites - the earliest being OWS Famita (1 May) and the latest being Malangen fjord and OWS Mike (13 May). This is at variance with the data of Falkenhaug et al. (1997b) which implies first reproduction around 1 March, and with the findings of Falkenhaug et al. (1997a), who detected significant numbers of adult female Calanus finmarchicus in the top $100 \mathrm{~m}$ of Malangen fjord in every month surveyed between February and December.

\section{Strategy I}

In Fig. 7 a we show a behaviour portrait illustrating the variation in maximum Year 5 density predicted by the Strategy I model variant as we change the critical food density $\left(F_{\mathrm{G}}\right)$ and the diapause growth rate reduction $(\Gamma)$. We see that with the default values of fooddependent mortality and reserves, this model variant passes the persistence test for all $F_{\mathrm{G}}<84$ and $0.27<\Gamma<$ 0.52 . Fig. $7 \mathrm{~b}$ to $\mathrm{d}$ show this pattern to be robust against removal of reserves and a factor of 2 increase in the food-dependent mortality coefficient. 
a)
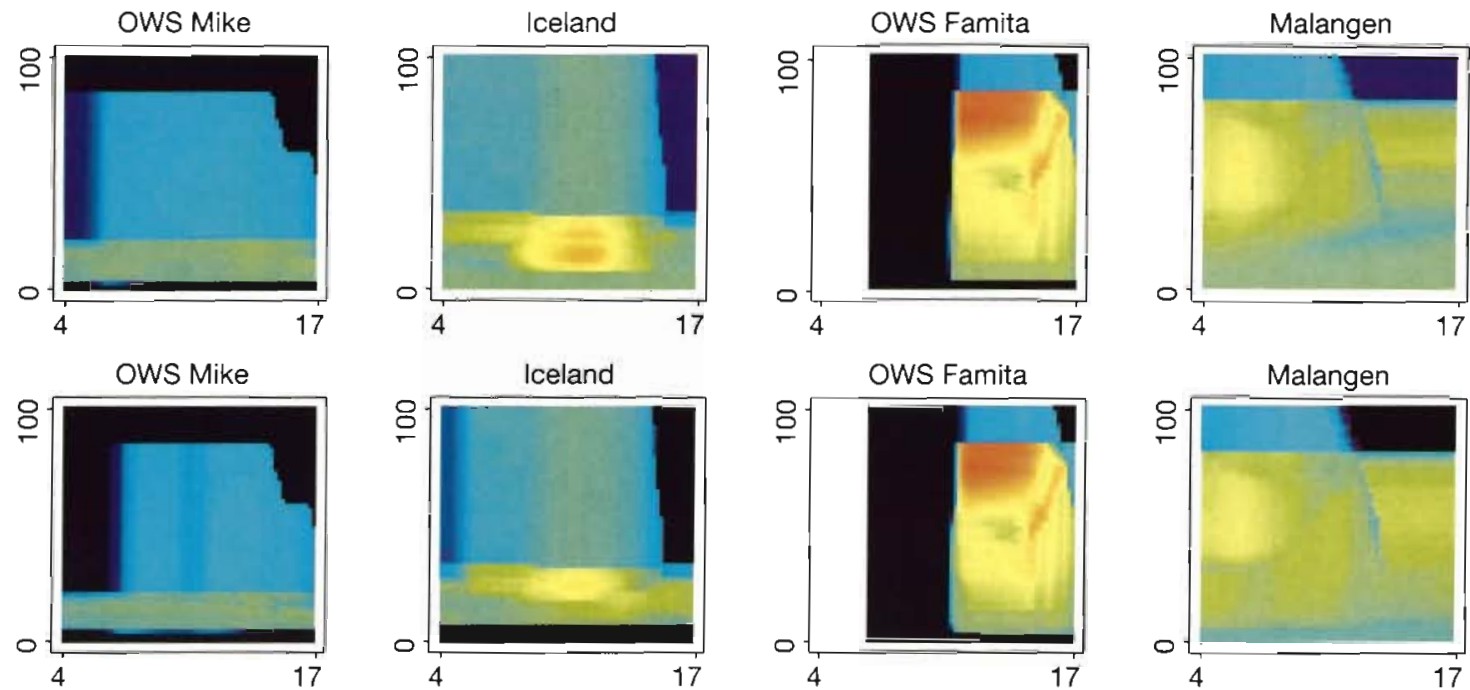

b)
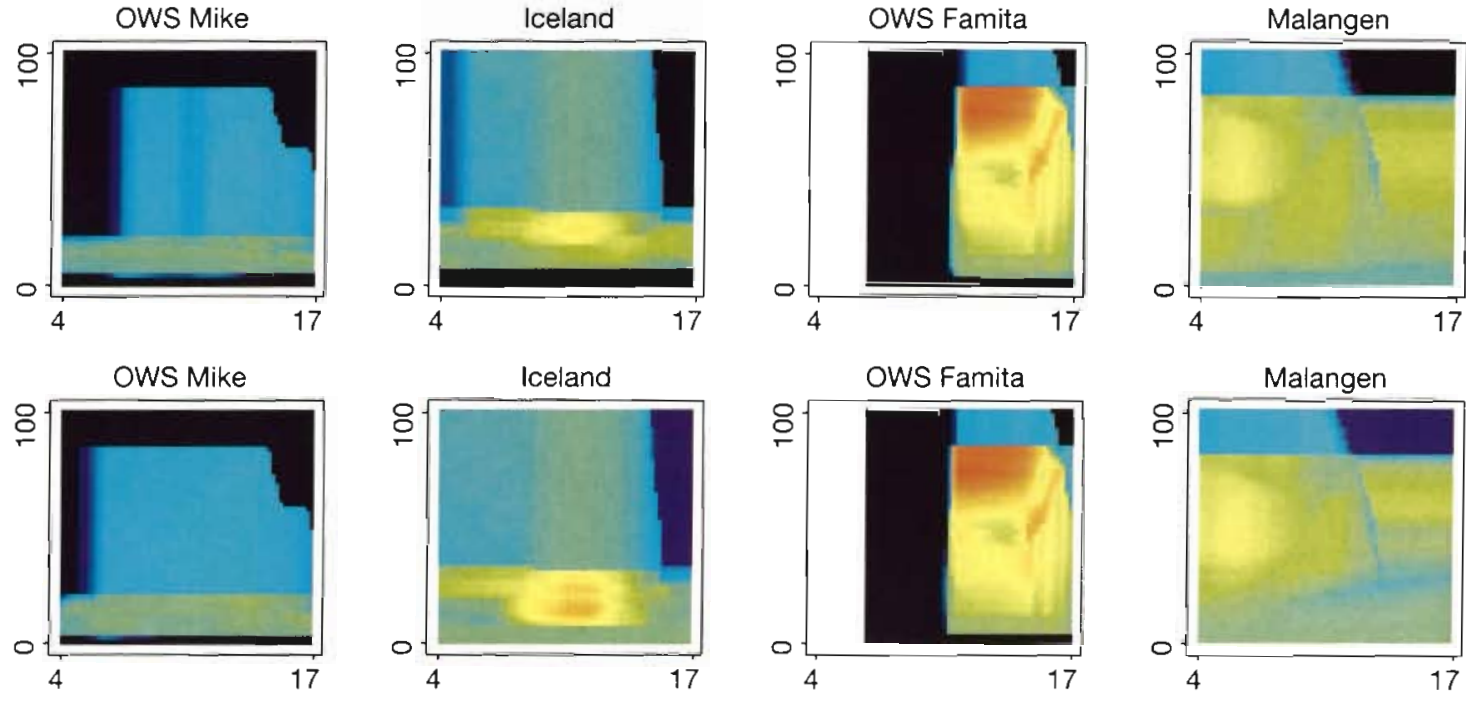

c)
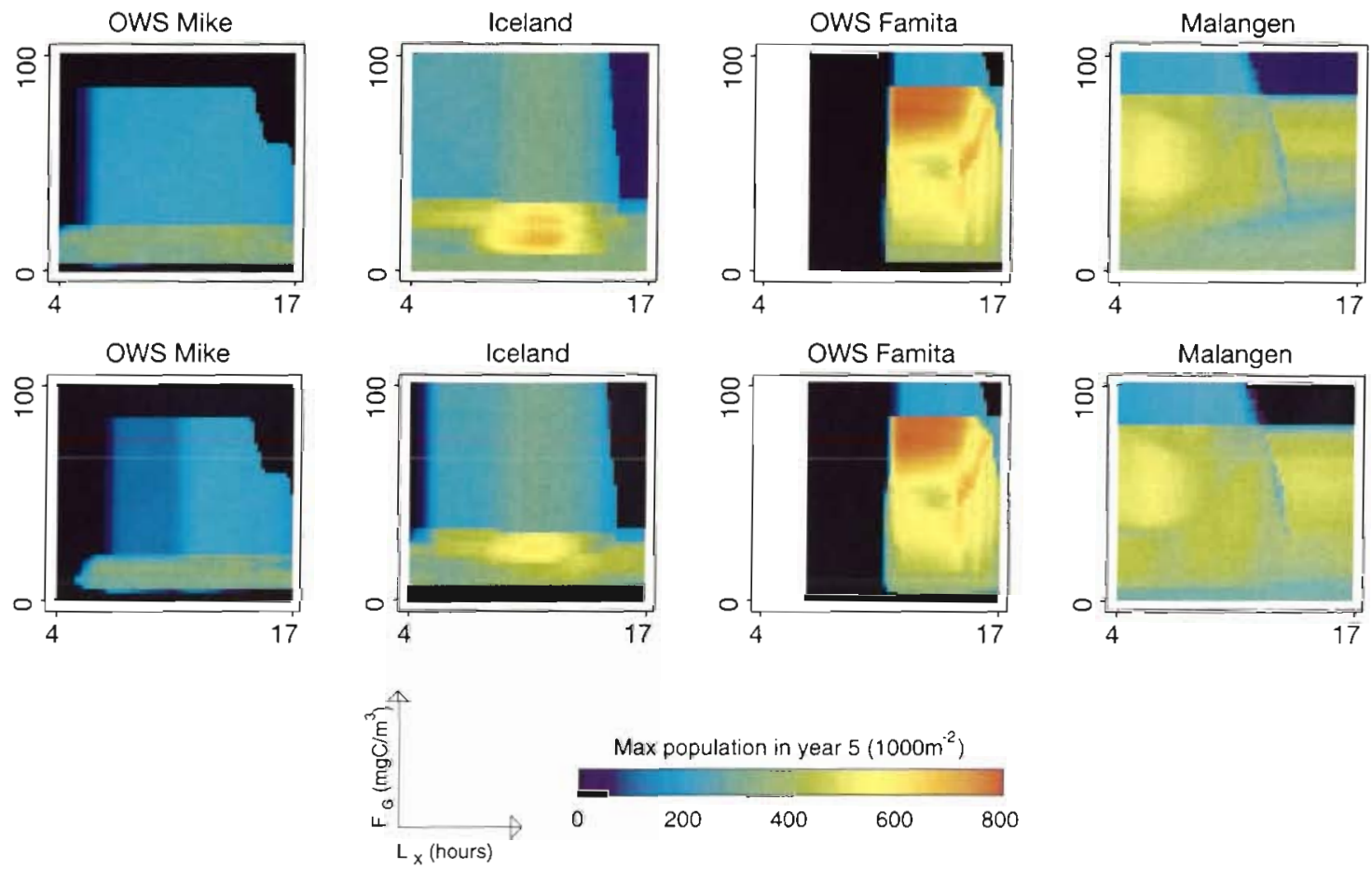

Fig. 6. Variation of population persistence under diapause control Strategy $M$ as the cue food abundance for initiation $\left(F_{G}\right)$ and daylength for exit $\left(L_{\mathrm{X}}\right)$ are varied. (a) Year 5 maximum population at 4 test sites with $F_{m}=5 \mathrm{mg} \mathrm{C} \mathrm{m}^{-3}$ and $R=30 \mathrm{~d}$, (b) Year 5 maximum population with $F_{m}=10 \mathrm{mg} \mathrm{C} \mathrm{m}^{-3}$ and $R=30 \mathrm{~d}$, (c) $F_{m}=5 \mathrm{mg} \mathrm{C} \mathrm{m}^{-3}$ and $R=0 \mathrm{~d}$, and (d) $F_{\mathrm{m}}=10 \mathrm{mg} \mathrm{C} \mathrm{m}^{-3}$ and $R=0 \mathrm{~d}$. All simulations started with $100 \mathrm{immature}$ adults in the surface on 17 March of Year 1 and had $\phi=4.32 \times 10^{-7} \mathrm{~d}^{-1} \mathrm{~m}^{-2}$

The right-hand column of Fig. 6 shows the stable generation patterns predicted by this model variant. The number of generations per year is unaltered from the Strategy M results at OWS Mike (1), on the Iceland shelf (2), and at OWS Famita (4/5), but has increased from 3 to 4 in Malagen fjord. The site-tosite variation in the timing of reproductive activity is now much more believable. In Malangen fjord, reproduction begins in late February, in general agreement with the data of Falkenhaug et al. (1997b). In the North Sea (OWS Famita) reproduction starts in early April in agreement with the initial assumptions of Carlotti \& Radach (1996). On the Iceland shelf females appear and begin to reproduce in mid-April, which is consistent with the data of Gislasson \& Assthorson (1996). In the Norwegian Sea (OWS Mike) the brief burst of reproductive activity remains, plausibly, in early May. 
a)
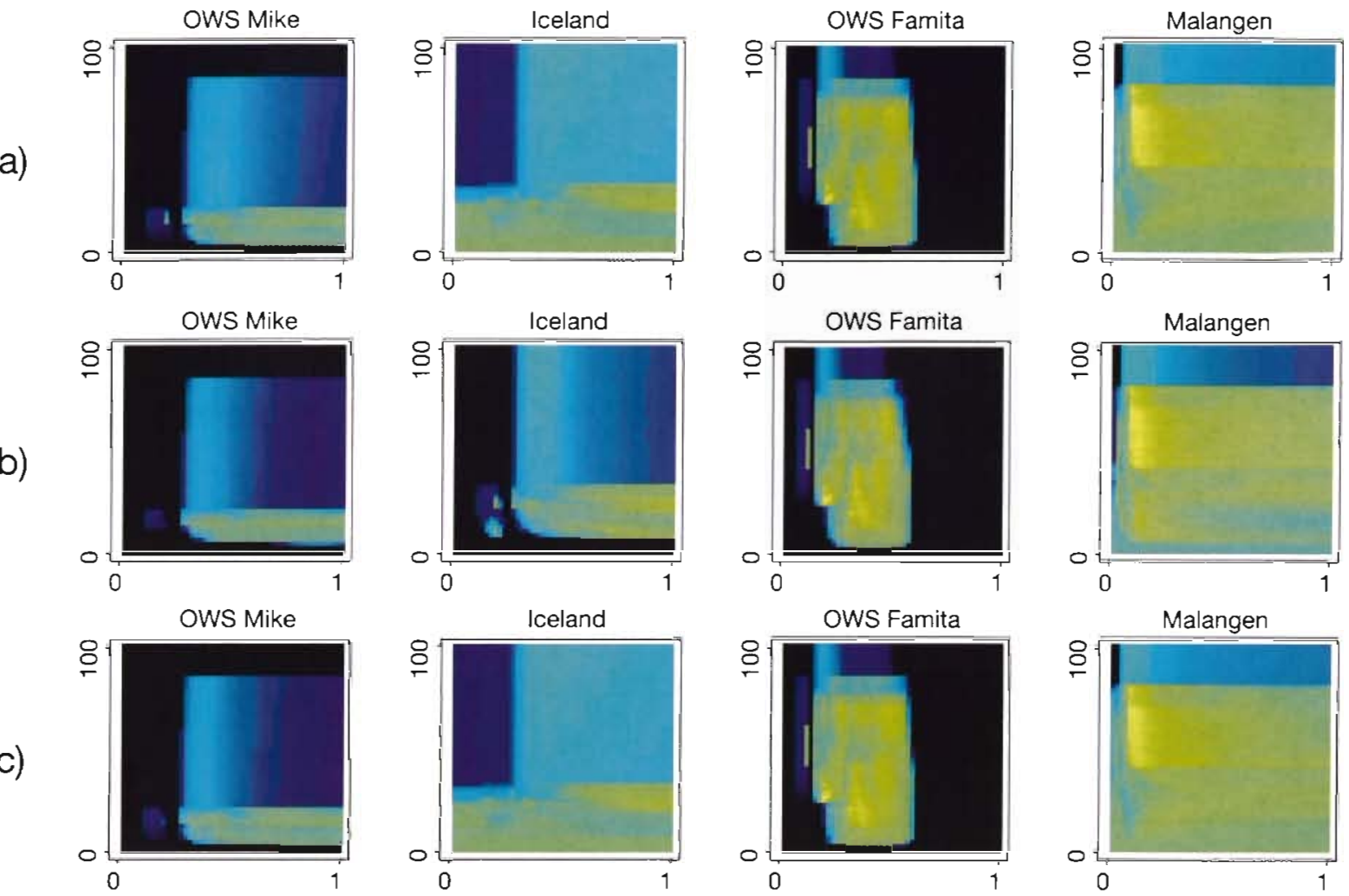

c)
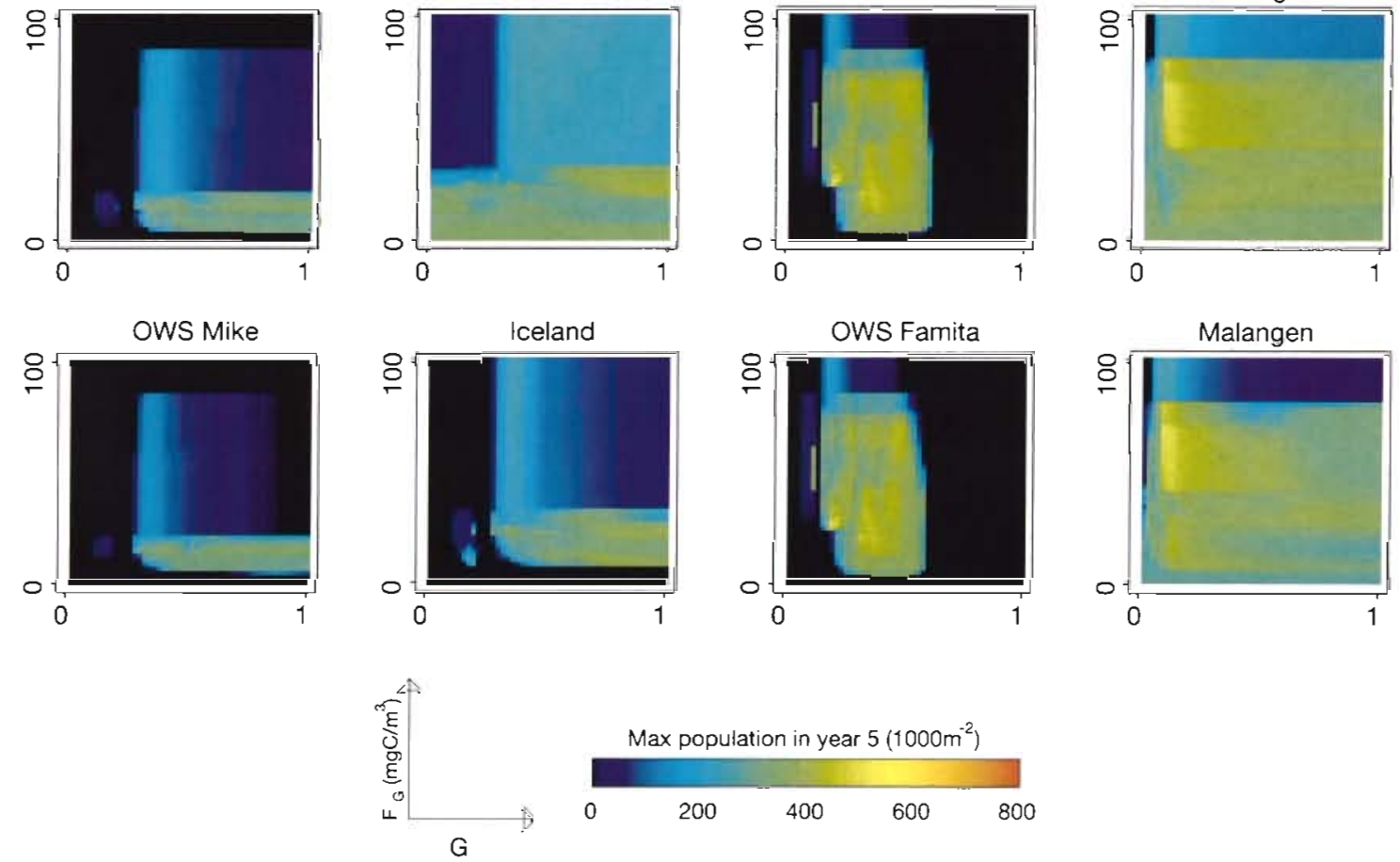

Fig. 7. Variation of population persistence under diapause control Strategy I as the cue food abundance for initiation $\left(F_{\mathrm{G}}\right)$ and diapause development reduction ( $\Gamma$ ) are varied. (a) Year 5 maximum population at 4 test sites with $F_{m}=5 \mathrm{mg} \mathrm{C} \mathrm{m}^{-3}$ and $R=30 \mathrm{~d}$, (b) Year 5 maximum population with $F_{m}=10 \mathrm{mg} \mathrm{C} \mathrm{m}^{-3}$ and $R=30 \mathrm{~d}$, (c) $F_{m}=5 \mathrm{mg} \mathrm{C} \mathrm{m}^{-3}$ and $R=0 \mathrm{~d}$, and (d) $F_{m}=10 \mathrm{mg} \mathrm{C} \mathrm{m}^{-3}$ and $R=0 \mathrm{~d}$. All simulations started with 100 immature adults in the surface on 17 March of Year 1 and had $\phi=4.32 \times 10^{-7} \mathrm{~d}^{-1} \mathrm{~m}^{-2}$

\section{DISCUSSION}

The mechanisms which control diapause in Calanus finmarchicus are difficult to unravel experimentally because the phenomenon occurs under deep ocean conditions which are essentially impossible to replicate in the laboratory. We have therefore adopted a strategic modelling approach. From a strictly logical point of view, this can only falsify specific instances of a finite number of hypotheses and can thus never hope to provide a unique identification of the control mechanism. However, combining failure to falsify particular hypothesis with important, but less well defined, considerations of biological plausibility, conceptual simplicity and behavioural robustness can lead to identification of a leading hypothesis from among those considered.

We set out 3 alternative hypotheses. First, that entry to and exit from diapause are controlled by photoperi- 
odic cues, with entry taking place only at the moult between Stages C4 and C5, and development being suspended during diapause. Second, that diapause is initiated by low food availability and ended by a photoperiod cue, with $\mathrm{C} 5$ development being suspended during diapause and subsequent C6 development being food dependent. Third, that entry to diapause and adult gonad maturation are both controlled by food availability, but C5 development continues at a reduced rate during diapause, which terminates when the stage is $80 \%$ complete. We denote these 3 hypotheses as Strategies D, M and I respectively.

The only further information we possess is that neither the choice of strategy, nor the parameters which determine its detailed operation, may vary with geographical position. This follows from the assumption that the controlling physiological and behavioural responses are genetically determined and the observation (Bucklin et al. 1996) that there is no genetic basis for discriminating between stocks of Calanus finmarchicus over the organisms's latitudinal range in the eastern Atlantic.

The first test to which we subjected our 3 hypotheses was that they should result in a persisting annual population cycle synchronised to the annual environmental cycle at all 4 test sites-using a single set of biological parameters. All 3 candidates passed this test; a result which we showed to be robust against large variation in our ancilliary biological assumptions about food-dependent mortality and immature adult reserves.

Our second test involved selecting a canonical set of control parameters for each strategy and investigating the stable annual cycle with a restricted group of parameter sets close to the canonical values. The requirement here was that the qualitative features of the predicted annual cycle at each test site should accord with what is observed. We found that the 3 hypothesised strategies performed very differently.

The pure photoperiodic strategy (D) results in annual cycles with an unrealistically large number of generations in the Norwegian Sea (OWS Mike) and on the Iceland shelf, and predicts no significant reproductive activity before 1 May at any site-in clear conflict with observations both in the North Sea (OWS Famita) and in Malagen fjord.

Strategy $M$, in which control occurs by a mixture of photoperiod cues and food availability, performs better in the Norwegian Sea and on the Iceland shelf but exhibits little site-to-site variation in the onset of reproduction. This is easily understood when it is observed that after diapause initiation, matters proceed in this model exactly as they do under Strategy $D$. In that case, the stable time at which adults appear in surface waters is later than the time at which sufficient food becomes available for Strategy $M$ to allow C6 individuals to mature into adults - so the maturation delay which this strategy permits does not occur.

By contrast, Strategy I, in which entry to diapause is controlled by food availability and whose duration is controlled by a reduced development rate in Stage C5, yields stable annual cycles which show plausible variation in both the number of generations per year and their temporal pattern at all 4 test sites. Thus we identify this control strategy as the only one of the 3 we have tested which has not been falsified.

This work cannot be regarded either as a demonstration that photoperiod cueing does not happen or that food availability cueing is the key diapause control mechanism. However, it does show that photoperiod cueing is not a neccessary prerequisite for Calanus finmarchicus to regularly re-ascend into surface waters in time to mature into reproductively active adults at appropriate times of year. It further suggests that any model involving photoperiod cueing of diapause exit is unlikely to be able to capture the relatively wide withinyear geographical variability of initial reproductive activity unless the requirement of genetic uniformity between geographical locations is relaxed.

An additional consideration in evaluating photoperiod cueing is the very sensitive nature of the optical sensory equipment which Calanus finmarchicus would require in order to perceive daylength accurately at overwintering depth. Taken together, these factors lead us to commend the hypothesis that diapause is initiated by low food abundance and controlled by normal development processes operating at a reduced rate, as worthy of further experimental exploration. This position is supported by the work of Fiksen \& Carlotti (1998), who studied a more complex individual model including an explicit representation of reserves. They found that overall fitness was maximised by a life-history including a diapause period whose commencement and duration were determined by the individual's reserve status.

Perhaps the most serious limitation of the study described in this paper is the simplifying assumption that an individual Calanus finmarchicus hatched at a given geographical location will overwinter and breed at the same location. Although the combination of this assumption and a strategically simplified individual model were the key to the wide-ranging tests made in this work, our conclusions cannot be regarded as entirely safe until they have been shown to be robust against realistic advective transport of individuals. A study with this aim, which is an extension of Bryant et al.'s (1998) study of the effects of basin-scale advection on the spatial distribution of individuals overwintering at depth, is currently underway and will be reported in a future publication. 
Acknowledgements. The authors wish to thank Professor C. Miller for a most thorough and helpful review. This work was supported by funding from the European Commission through contract MAS3-CT95-0039.

\section{LITERATURE CITED}

Bryant AD, Hainbucher D, Heath M (1998) Basin scale advection and population persistence of Calanus finmarchicus. Fish Oceanogr 7:235-244

Bucklin A, Sundt RC, Dahle G (1996) The population genetics of Calanus finmarchicus in the North Atlantic. Ophelia 44 $29-45$

Carlotti F, Radach G (1996) Seasonal dynamics of phytoplankton and Calanus finmarchicus in the North Sea as revealed by a coupled one-dimensional. Limnol Oceanogr $41(3): 522-539$

Falkenhaug T (1996) Distributional and seasonal patterns of ctenophores in Malangen, Northern Norway. Mar Ecol Prog Ser 140:59-70

Falkenhaug T, Tande KS, Semenova T (1997a) Diel, seasonal and ontogenic variations in the vertical distributions of 4 marine copepods. Mar Ecol Prog Ser 149:105-119

Falkenhaug T, Tande K, Timonin A (1997b) Spatio-temporal patterns in the copepod community in Malangen, Northern Norway. J Plankton Res 19(4):449-468

Fiksen O, Carlotti F (1998) A model of optimal life-history and diel vertical migration in Calanus finmarchicus. Sarsia 83 $129-147$

Gislasson A, Astthorsson OS (1996) Seasonal development of Calanus finmarchicus along an inshore-offshore gradient southwest of Iceland. Ophelia 44:71-84

Grist EPM, Gurney WSC (1995) Stage-specificity and the synchronisation of life-cycles to periodic environments. J Math Biol 34:123-147

Gurney WSC, Crowley PH, Nisbet RM (1994) Stage-specific quiescence as a mechanism for synchronising life-cycles to seasons. Theor Popul Biol 46:319-343

Heath M. Jonasdottir S (1999) Distribution and abundance of over wintering Calanus in the Faroe-Shetland Channel Fish Oceanogr (in press)

Hind AT, Gurney WSG (1998) Life-cycle synchrony in a marine copepod. Arch Hydrobiol Spec Iss Adv Limnol 52: $327-337$

Hirche HJ (1996a) The reproductive biology of the marine copepod, Calanus finmarchicus-a review. Ophelia 44: $111-128$

Hirche HJ (1996b) Diapause in the marine copepod, Calanus finmarchicus - a review. Ophelia 44:129-143

Hirche HJ, Kwasniewski S (1997) Distribution, reproduction and development of Calanus species in the Northeast Atlantic in relation to environmental conditions. J Mar Syst 10:299-317

Hirche HJ, Meyer U, Niehoff B (1997) Egg production of

Editorial responsibility: Thomas Kiorboe (Contributing Editor), Charlottenlund, Denmark
Calanus finmarchicus: effect of temperature, food and season. Mar Biol 127:609-620

Ingvarsdottir A (1998) Seasonal changes in physiology and chemical composition of Calanus finmarchicus late copepediate stages. $\mathrm{PhD}$ thesis, University of Aberdeen

Ingvarsdottir A, Houlihan DF, Heath MR, Hay SJ (1999) Seasonal changes in respiration rates of Calanus finmarchicus (Gunnerus) at copepodite stage V. Fish Oceanogr (in press)

Iqbal $M$ (1983) An introduction to solar radiation. Academic Press, Ontario

Irigioen X, Head R, Klenke U, Meyer-Harms B, Harbour D Niehoff $B$, Hirche HJ, Harris R (1998) A high frequency time series at weathership $M$, Norwegian Sea, during the 1997 spring bloom: feeding of adult female Calanus finmarchicus. Mar Ecol Prog Ser 172:127-137

Jonasdottir S (1999) Lipid content and depletion in Calanus finmarchicus during overwintering in the Faroe-Shetland Channel. Fish Oceanogr (in press)

Kiorboe T (1989) Phytoplankton growth rate and nitrogen content: implications for feeding and fecundity in a herbivorous copepod. Mar Ecol Prog Ser 55:229-234

Marshall SM, Orr AP (1955) The biology of a marine copepod Calanus finmarchicus (Gunnerus). Oliver and Boyd, Edinburgh

Miller CB, Grigg $H$ (1991) An experimental study of the resting phase in Calanus finmarchicus (Gunnerus). Bull Plankton Soc Jpn (Spec Vol: Proc 4th Intl Conf Copepoda) $479-493$

Miller CB, Tande KS (1993) Stage duration estimation for Calanus populations, a modelling study. Mar Ecol Prog Ser 102:15-34

Miller CB, Cowles T J, Wiebe PH, Copley NJ, Grigg H (1991) Phenology in Calanus finmarchicus; hypotheses about control mechanisms. Mar Ecol Prog Ser 72:79-91

Ohman MD, Runge JA (1994) Sustained fecundity when phytoplankton resources are in short supply: omnivory by Calanus finmarchicus in the gulf of St Lawrence. Limnol Oceanogr 39:21-36

Østvedt OJ (1955) Zooplankton investigations from weathership $M$ in the Norwegian Sea, 1948-49. Hvaldrådets Skr 40:1-93

Paffenhofer GA (1971) Grazing and ingestion rates of nauplii, copepedites and adults of the marine copepod Calanus heligolandicus. Mar Biol 11:286-298

Richardson K, Jønasdottir S, Hay SJ, Christoffersen A (1999) Calanus finmarchicus production and food availability in the Faroe-Shetland Channel and northern North Sea: October-March. Fish Oceanogr (in press)

Steele JH, Henderson EH (1995) Predation control of plankton demography. ICES J Mar Sci 52:565-573

Tande KS (1988) Aspects of developmental and mortality rates in Calanus finmarchicus related to equiproportional development. Mar Ecol Prog Ser 44:51-58

Truscott JE, Brindley J (1994) Plankton populations as excitable systems. Bull Math Biol 56:981-998

Submitted: March 21, 1999; Accepted: July 7, 1999

Proofs received from author(s): February 18, 2000 